\title{
CLASSIFYING AND MAPPING OF VEGETATED AREA IN AL- BAHA REGION, SAUDI ARABIA USING REMOTE SENSING. II. THE RELATIONSHIP BETWEEN ELEVATION, LAND SURFACE DAY TEMPERATURE, AND VEGETATION DENSITY.
} Arabia.

ABSTRACT Classifying and mapping of vegetated area in Al- Baha region, Saudi Arabia using remote sensing shows that the mediumhigh density vegetation is mostly found at the central part of Al-Baha region separating the highlands and the low lands. Results obtained show that only $862.5 \mathrm{~km} 2(7.7 \%)$ Al-Baha region is covered with medium-high density vegetation found mainly at the $6-15 \mathrm{~km}$ width horizontal central belt (at districts of Al-Mandaq, Al-Baha and south Baljurashi) along high foggy mountainous plateau. Whereas, about $65 \%$ of Al-Baha region has very low-none density vegetation mainly occurred extensively at Tihama low plain towards the Red Sea and at the north-eastern desert plain. In addition, study reveals that the highlands of Al-Baha have the most numbers of trees represents the areas of the highest elevations in the region (range between 1940 and $2366 \mathrm{~m}$ above sea level. This indicates that there is relationship between this elevation range with medium to high vegetation density. Similarly, the low surface temperatures are mainly located at the central belt across Al-Baha region. When overlaid with medium-high vegetation density zone with the temperature map, it was visually observed that it almost fit with lower temperature zone of less than $15^{\circ} \mathrm{C}$. This also indicates that there is relationship between lower temperature with medium-high vegetation density.

\section{KEYWORDS : Classifying, mapping, vegetated area , Al- Baha region, Saudi Arabia , remote sensing. elevation, ,surface day} temperature

\section{INTRODUCTION}

Al-Baha is the smallest region among the 13 administration regions of Saudi Arabia with an area of $11.000 \mathrm{~km}^{2}$ and represents $0.6 \%$ of the total land area of the Country.

AlBaha region is located in the southwest part of Saudi Arabia and occupies a portion of the mountains of Al-Sarawat. It is bounded on the north and west by Makkah, on the south and east by Asir region, the Red Sea coast city of Al Qunfuda on the west and located between the longitudes $41^{\circ}$ and $42^{\circ}$ east and between $19^{\circ}$ and $20^{\circ}$ latitudes south.

This study area is located within an elevation of 130-2450 m above sea level. It has three main zone between dry coastal plain, Rocky Mountains that face west and semi Desert Mountains that face east. It has a wide variety of woodland, shrubland, grassland, and forest habitats accompanied by many plant species (El-Juhany, and Aref(2012).

Al Baha topography is quite varies and can be divided geographically into three distinct parts as follows:

- Sarah, which contains the high mountains characterized by temperate weather and rich plant cover due to relatively high

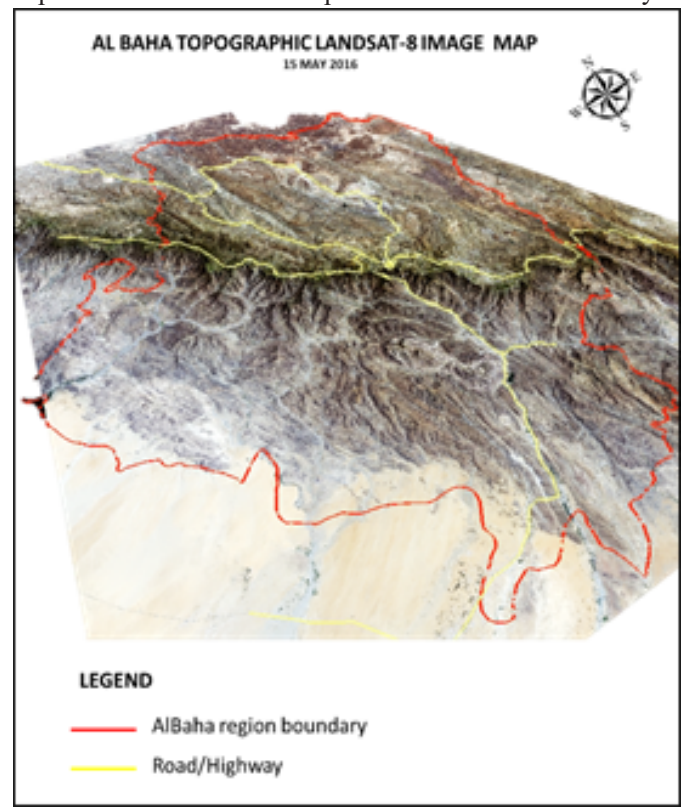

Figure F.2 : Topography at AIBaha Region shown by LANDSAT8 image annual rainfall. In some parts are almost flat and undulating plateaus, the altitude ranges between 1700 to the east and from 2000 to $2500 \mathrm{~m}$ toward the west at Jabal Alzzrayeb, rising up to $2565 \mathrm{~m}$ at Al Hamd (north-east of Al Baha city).

- Tehama, which is the lowland coastal area to the west of the Sarah characterized by very hot and humid weather and very little rainfall average. It is a sandy flat to undulating plain, ranging from 50 to $150(200 \mathrm{~m})$ and narrowing toward northwest slopes and touching the foothills at $350 \mathrm{~m}$. It has a medium to steep slope intersected by valley gullies, descending gradually toward the west, the altitude ranges from 200 (400) to 2001 and 2200 west of Al Baha city and Uwera and between 2000 and 2100 m west of Baljurashi. The plain is intersected by many valleys mainly wadi Nawan, wadi Al Hasaba, wadi Malal, wadi Nabira and wadi Uleib.

- Eastern hills, characterized by an altitude of 1550 to 1900 meters above sea level with cool winters, hot summers and sparse plant cover. It gradually descends toward the east and northeast, dissected by several valleys such as the wadi Jazab and wadi Ayna. The altitude ranges between 1300 and $1700 \mathrm{~m}$. AlBaha topography is shown at Figure F.2. and Figure F.3. (Alaklabi, A. et al, 2016)

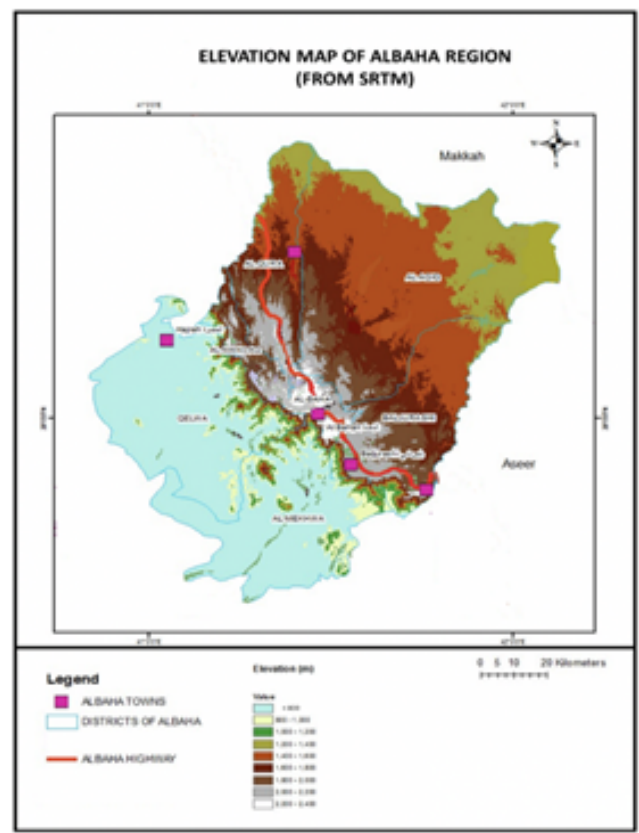

Figure F.3: Elevation Map of Al-Baha region. 
The climate of Al Baha region is influenced by its varying topography. It is generally moderate in summer and cold in winter, with average temperature ranging between 12 and $23^{\circ} \mathrm{C}$. Due to its location at 2,500 meters above sea level, Al Baha's climate is comparatively cold in winter $\left(10-22^{\circ} \mathrm{C}\right)$ and mild in summer $\left(22-32^{\circ} \mathrm{C}\right)$. The region is characterized by rainfall throughout the year also features a lot of fog especially in the mountains and low temperatures in summer and winter which attracts visitors looking for a moderate climate and pristine, scenic views. (Alaklabi, A. et al, 2016)

Topographically, the climate at AlBaha region varies with district, the Tehama area, which is down on the coast, the climate is hot in the summer and warm in the winter. Humidity ranges from $52 \%-67 \%$. Average rainfall in Al-Aqiq and Al-Mikhwah areas is 100-200 mm, temperature is $20-37^{\circ} \mathrm{C}$ in winter and $36-51^{\circ} \mathrm{C}$ in hot summer (Mousa, Ibrahim, Mohamed 2010)

While in the mountainous region, which is known as As-Sarah, the weather is cooler in summer and winter. Rainfall in the mountainous region lies in the range of 229 to 581 millimetres. The average throughout the whole region is 100 to 250 Classifying and mapping vegetation is an important technical task for managing natural resources as vegetation provides a base for all living beings and plays an essential role in affecting global climate change, such as influencing terrestrial $\mathrm{CO}_{2}$ (Xiangming et al. 2004)

\section{Vegetation mapping}

Vegetation mapping also presents valuable information for understanding the natural and man-made environments through quantifying vegetation cover from local to regional scales at a given time point or over a continuous period. It is pertinent to acquire current status of vegetation cover to initiate vegetation protection and restoration programs. (Egbert et al. 2002; He et al. 2005).

Generally, the primary objective of the vegetation-mapping inventory is to produce high quality, standardized maps and associated data sets of vegetation and other land-cover occurring within forests. This information fills and complements a wide variety of resource assessment, forest management, and conservation needs.

Conventionally, vegetation mapping requires ground inventory carried out under severe climate such as dry air, high temperature and strong sun which affect human work capability rendering result accuracy degrading. In addition, it requires a lot of money, time, labour, many tools and helpers. Hence, estimation of vegetation density mapping at a relatively low cost, less laborious and with little time consumption is desirable. Since the past three decades, vegetation inventory has become more cost-effective, less time-consuming and less labor-intensive by using remote sensing data. Satellite remote sensing have proven to be effective technology for mapping forest vegetation at landscape to regional scale.

In remote sensing technique, vegetation density can be directly indicated by vegetation indices, which theoretically based on the observation that different vegetation surfaces reflect different types of light differently. Although there are several vegetation indices formulated, the most widely used is the Normalized Difference Vegetation Index (NDVI), which is an index of plant "greenness" or photosynthetic activity

Photosynthetically active vegetation, in particular, absorbs most of the red light that hits it while reflecting much of the near infrared light. Vegetation that is dead or stressed reflects more red light and less near infrared light. Likewise, non-vegetated surfaces have a much more even reflectance across the light spectrum (Marika et al, 2018).

By transforming raw satellite data into NDVI values, researchers can create images and other products that give a rough measure of vegetation type, amount, and condition on land surfaces around the world. NDVI is especially useful for continental- to global-scale vegetation monitoring because it can compensate for changing illumination conditions, surface slope, and viewing angle. That said, NDVI does tend to saturate over dense vegetation and is sensitive to underlying soil colour (Yengoh G.T et. al. 2014)

NDVI values can be averaged over time to establish "normal" growing conditions in a region for a given time of year. Further analysis can then characterize the health of vegetation in that place relative to the norm.
When analyzed through time, NDVI can reveal where vegetation is thriving and where it is under stress, as well as changes in vegetation due to human activities such as deforestation, natural disturbances such as wild fires, or changes in plants' phenological stage (Lillesand et al, 2004).

\section{Extent and Distribution of Vegetated Categories in Al-Baha.}

NDVI map extracted from LANDSAT-8 satellite image depicts that there are a total of 7,428.9 $\mathrm{km}^{2}(67.2 \%)$ of vegetated area in Al-Baha comprising of high vegetation about $61.8 \mathrm{~km}^{2}(0.6 \%)$, medium vegetation $790.7 \mathrm{~km}^{2}(7.1 \%)$, low vegetation $2,400.6 \mathrm{~km}^{2}(21.7 \%)$, and very low vegetation $14,175.8 \mathrm{~km}^{2}(37.8 \%)$, meanwhile the none vegetation is about $3,630.8 \mathrm{~km}^{2}(32.8 \%)$ (Al-Ghamdi A. S. 2020).

District Al-Mandaq has the largest medium-high density vegetation zone with $269.8 \mathrm{~km}^{2}$ which covers $74.8 \%$ of the district. Meanwhile, district Qelwa has the most extensive of none vegetation with 1,336.8 $\mathrm{km}^{2}(59.9 \%)$ and district Al-Aqiq has the most very low vegetation zone with $1,917.9 \mathrm{~km}^{2}(52.3 \%)$. Al-Ghamdi A. S. (2020)

Observations reveals that most of the high vegetated (high and medium NDVI) are located at the high plateau $3 \mathrm{~km}$ width horizontal belt central of Al-Baha comprising at districts of Al-Mandaq, Al-Baha and southern part of Baljurashi. This area totalled $860 \mathrm{~km}$ covers only $7.7 \%$ of Al-Baha are mainly located in the mountains above Aqabat Hizna and around Baljurashi, are mostly fog-affected seaward-facing mountain slopes. Al-Ghamdi A. S. (2020)

These are the zone that wild olives found besides the abundance juniper and acacia species. As was reported by Al-Klabi et al, (2016) that these landscapes support dense deciduous woodland dominated by the tree J. procera, together with A. origena. They observed that as the influence of fog decreases further north-east or south-west, forest and woodland is replaced by sparse woodland or shrubland dominated by $A$. asak, A. tortilis and A. ehrenbergiana. Beyond this, the vegetation becomes sparser and finally gives way to open semi-desert. El-Juhany, and Aref, (2012)

\section{Accuracy Assessment.}

Accuracy assessment were conducted to fifty (50) plots of $30 \mathrm{~m} \times 30 \mathrm{~m}$ set up on Google Earth map with ten (10) plots distributed evenly for every vegetation density. At each plot, percentage vegetation cover was estimated. All of the images at Google earth of these plots are from Quickbird/SPOT satellite, which have a resolution of $0.5 \mathrm{mx} 0.5 \mathrm{~m} / 5 \mathrm{~m}$ $\mathrm{x} 5 \mathrm{~m}$, which is high enough to discern vegetation cover percentage at AL Baha region.

Assessment was based how accurate vegetation density interpreted from LANDSAT-8 image to the vegetation cover percentage estimated from Google Earth Quickbird image. Results shows that out of 50 plots, 48 plots were correctly categorised indicating the accuracy as 96\% as shown in Table 34

Table T1.3: Vegetation Density in Relation with Number of Correct Plot

\begin{tabular}{|c|c|c|c|}
\hline $\begin{array}{c}\text { Vegetation } \\
\text { Density }\end{array}$ & NDVI value & Plots Correct & $\begin{array}{c}\text { Percentage } \\
\text { Correct (\%) }\end{array}$ \\
\hline High & $0.30-1.00$ & 10 & 100 \\
\hline Medium & $0.20-0.30$ & 9 & 90 \\
\hline Low & $0.15-0.20$ & 9 & 90 \\
\hline Very Low & $0.10-0.15$ & 10 & 100 \\
\hline None & $0.00-0.10$ & 10 & 100 \\
\hline TOTAL & & 48 & $\mathbf{9 6}$ \\
\hline
\end{tabular}

\section{MATERIALAND METHOD.}

In this study, the technology used is satellite Remote Sensing. Following para describe the material, data and method applied.

\section{MATERIALAND DATA}

In this study, software used are as follows:

- $\quad$ ERDAS Imagine 2014 - an image processing software

- ArcGIS ver 10.3 - a GIS software to do analysis information extracted from satellite image

Whereas, data used in this project are as follows:

- Satellite image LANDSAT-8 dated 15 May 2016 (resolution 30m x 30m) 
- Digital boundary of Al-Baha region and district

- Quickbird/SPOT (from Google Earth)

\section{METHOD}

In this study, three main components involved namely data collection, data analysis and field work.

Satellite image LANDSAT-8 dated 15 May 2016 was used as the primary source for data extraction to identify vegetated area at Al-Baha region. Upon downloaded from the USGS website, Image LANDSAT8 was processed for Normalised Differential Vegetation Indices (NDVI) to demarcate areas with vegetation or chlorophyll. Detail activities $\mathrm{s}$ of the workflow is shown in the next para.

Remote Sensing data acquired from LANDSAT- 8 satellite imagery ( 15 May 2016) path/row 168/46 were downloaded from the United State Geological survey (USGS) website. LANDSAT-8 images provides moderate-resolution imagery, from 15 meters to 100 meters, of earth's land surface and polar regions, Landsat 8 operates in the visible, nearinfrared, short wave infrared, and thermal infrared spectrums. Landsat 8 captures more than 700 scenes a day. It consist of nine spectral bands with a spatial resolution of 30 meters for Bands 1 to 7 and 9 while band 8 is 15 meters.

The LANDSAT- 8 bands are :

band 1 (ultra-blue $0.433-0.453 \mu \mathrm{m}$ ),

band 2 (blue- $0.450-0.515 \mu \mathrm{m}$ ),

band 3 (green-0.525-0.600 $\mu \mathrm{m}$ ),

band $4($ red $0.630-0.680 \mu \mathrm{m})$

band 5 (near infrared $0.845-0.885 \mu \mathrm{m}$ ), band 6 (short infrared 1.560 $1.660 \mu \mathrm{m})$, band 7 (short infrared $2.100-2.300 \mu \mathrm{m})$, band 8 (panchromatic 0.500-0.680 $\mu \mathrm{m}$ ), band 9 (cirrus 1.360-1.390 $\mu \mathrm{m}$ ).

Approximate scene size is $170 \mathrm{~km}$ north-south by $183 \mathrm{~km}$ east-west (Roy et al, 2016)

\section{RESULT}

Relationship between Vegetation Density and Land Surface Day Temperature

Land surface temperature is a measurement of how hot the land is to the touch. It differs from air temperature because land heats and cools more quickly than air.

In this study, temperature was derived from LANDSAT- 8 image, which is actually a land surface day temperature.

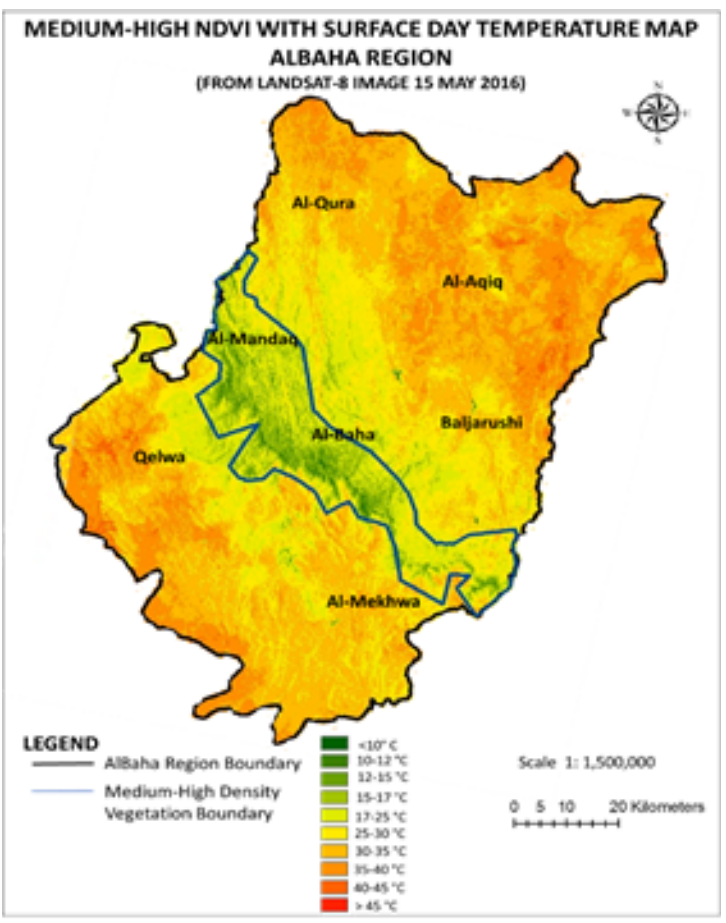

Figure F1.10, shows that the low surface

Figure F1.10: Surface Temperature Map of AlBaha Region temperatures are mainly located at the central belt across Al-Baha region. When overlaid with medium-high vegetation density zone with the temperature map, it was visually observed that it almost fit with lower temperature zone of less than $15^{\circ} \mathrm{C}$. This indicates that there is relationship between lower temperature with medium-high vegetation density.

\section{Relationship between Vegetation and Elevation}

Many studies has associated vegetation and elevation. In this study, visual observation reveals that most of the medium-high vegetation zone study is located at the higher elevation of $>1,500 \mathrm{~m}$ (Figure 11, and.12.

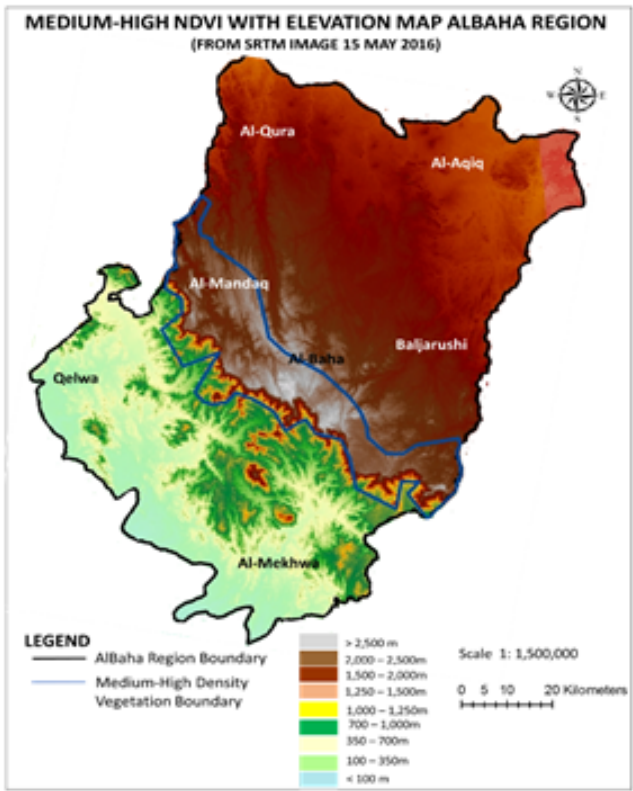

Figure F1.11: Vegetation Density with Elevation Map of AlBaha Region

Similar study and conclusion were derived by Ghazal (2015) who observed that the high Asir mountains vegetation zone, which extends from $2000 \mathrm{~m}$ to summits, of semiarid climate is abundance with vegetation of juniper

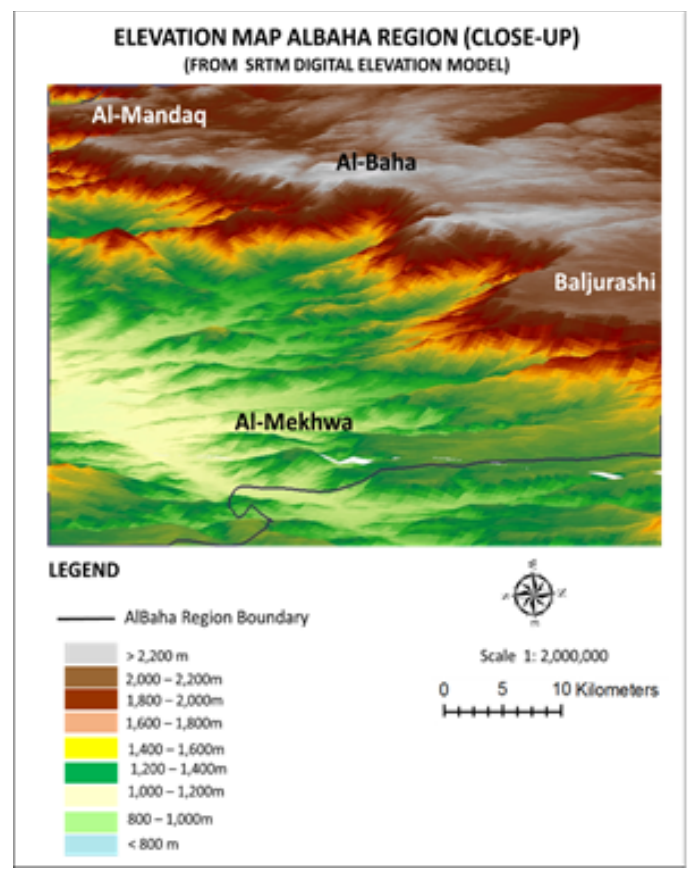

Figure.12: Elevation Map of Al-Baha Region (3D)

forest with Acacia origena and Olea europaea subsp. cuspidata and many other shrubs such as Clutia myricoides, Maytenus arbutifolia and several annual and perennial ground cover species. 


\section{DISCUSSION}

The results shows that the medium-high density vegetation is mostly found at the central part of Al-Baha region separating the highlands and the lowlands. This project reaffirms the study conducted by many researches including by Al-Khulaidy (2013) whom referred the mountainous region of Al-Baha as the most plant diversify region in Saudi Arabia. Similar study by El Juhany and Aref, (2012) also reveals that the highlands of Al-Baha have the most numbers of trees includes the area from the Baha City to Gazzanah in the south represents the areas of the highest elevations in the region (range between 1940 and $2366 \mathrm{~m}$ above sea level.

Relationship study between NDVI and vegetation cover percentage in this study depicts that NDVI value of $0.20-1.00$ which indicate vegetation presence cover more than $60 \%$ of Al-Baha region. This is probably due to vegetation here may not only be trees but other plant form such as herbs and shrub. This is according to studies done by Aldhebiani and Howladar, (2013) at Al-Baha whom observed that herbs dominated the vegetation of their study area $(51 \%)$ followed with shrubs $(20 \%)$, trees $(18 \%)$ and other individuals ranged shrubs to trees $(8 \%)$ and herbs to shrubs $(2 \%)$

It was observed that the medium-high density vegetation zone also encompassed the Amdan forest which abounds in olive trees, Ara'r shrubs and other natural vegetation and Wadi Feig which is encircled by a green valley littered with apricot, pomegranate and grape orchards. It also covers Wadi Al Ageeg forest which is abounds in various fruit trees and tall lotus trees.

\section{CONCLUSION}

This project has provided a comprehensive report on vegetation mapping at Al-Baha region as a base for the next phase of the 'Inventory and Mapping Wild Olive Tree At Al-Baha" project. Results obtained show that Al-Baha is only $862.5 \mathrm{~km}^{2}(7.7 \%)$ covered with medium-high density vegetation mainly at the $6-15 \mathrm{~km}$ width horizontal central belt (at districts of Al-Mandaq, Al-Baha and south Baljurashi) along high foggy mountainous plateau. This is the zone that will be emphasized for the next project as observation shows that this zone has percent ground cover $>60 \%$ indicating has high potential for wild olive tree presence. Meanwhile, about $65 \%$ of Al-Baha region has very low-none density vegetation mainly occurred extensively at Tihama low plain towards the Red Sea and at the north-eastern desert plain

\section{Acknowledgements}

This research was funded by chair of Sheikh Said Ben Ali Alangari for olives research at Albaha University, Albaha, Saudi Arabia. The Author also acknowledge with thanks the Deanship of Scientific Research (DSP) at Albaha University for their technical support. Thanks, extended to Geoprecision Tech Sdn Bhd (GPT) and Universiti Putra Malaysia (UPM) for their technical help

\section{REFERENCES}

1. Al-Aklabi, Ibrahim A. Arif, S. O. Bafeel, A. H. Alfarhan, A. Ahamed, J. Thomas, M.A. Bakir (2016), Nucleotide based validation of the endangered plant Diospyros mespiliformis (Ebenaceae) by evaluating short sequence region of plastid rbcL gene, POJ, 7 (2) (2014), pp. 102-107 (102)

2. Al-Ghamdi, Abdullah Saleh (2020 a). Classifying and mapping of vegetated area in AlBaha region, Saudi Arabia using remote sensing. I. Extent and distribution of ground vegetated cover categories. (Under publication).

3. Al-Khulaidi A. (2013), Flora of Yemen. The Sustainable Natural Resource Management Project (SNRMP II), EPA and UNDP, Republic of Yemen (2013).

4. Aldhebiani, A. Y., Howladar S. M. (2013), Floristic Diversity and Environmental Relations in Two Valleys, South West Saudi Arabia, International Journal of Science and Relations in Two Valleys, South West Saudi Arabia, International Journal of Scien (IJSR), Volume 4 Issue 2, February 2015, ISSN (Online): 2319-7064.

5. Egbert, S., S. Park, K. Price, R. Lee, J. Wu, M.D. Nellis. 2002. Using Conservation Reserve Program maps derived from satellite imagery to characterize landscape structure. Computers and Electronics in Agriculture 37(1-3):141-156.

6. El-Juhany Loutfy I. and Ibrahim M. Aref (2012), The Present Status of the Natural Forests in the Southwestern Saudi Arabia 2-Baha Forests, World Applied Sciences Journal 20 (2): 271-281, 2012, ISSN 1818-4952.

7. Ghazal (2015).

8. He, C, Q. Zhang, Y. Li, X. Li, P. Shi, (2005) Zoning grassland protection area using remote sensing and cellular automata modeling - a case study in Xilingol steppe grassland in northern China. Journal of Arid Environments 63 (2005) 814-826.

9. Lillesand, T.R. Kiefer, J. Chipman, (2004), Remote Sensing and Image Interpretation, (5th ed), John Wiley, New York

10. Marika R. Tatishvili, Irine P. Mkurnalidze, Inga G. Samkharadze, Lasha N. Chinchaladze, (2018), Application of Satellite Imagenary in Forestry for Georgia, Journal of the Georgian Geophysical Society, Vol 21. No 1(2018)

11. Moussa, Ibrahim, Mohamed (2010), Study of cystic echinococcosis in slaughtered animals in Al Baha region, Saudi Arabia: interaction between some biotic and abiotic factors, Acta Trop., 113 (1): (2010), pp. 26-33.

12. Roy D.K, Kovalskyy V., Zhang H.K, Vermote E.F, Yan L, Kumar S.S., Egorov A. (2016), Characterization of Landsat-7 to Landsat-8 reflective wavelength and normalized difference vegetation index continuity Remote Sensing of Environment Volume 185, difference vegetation index cont
November 2016, Pages 57-70
13. Xiangming Xiao, Qingyuan Zhang, Bobby Braswell, Shawn Urbanski, Stephen Boles, Steven Wofsy, Berrien Moore III, and Dennis Ojima. (2004) Modeling gross primary production of temperate deciduous broadleaf forest using satellite images and climate data. Remote Sensing of Environment 91 (2004) 256 - 270.

14. Yengoh, Genesis T., Dent, David, Olsson, Lennart, Tengberg, and A. E., Tucker III, Compton J. (2014). The use of the Normalized Difference Vegetation Index (NDVI) to assess land degradation at multiple scales. Current status, future trends, and practical considerations, Springer Briefs in Environmental Science Print ISBN: 978-3-31924110-4, Electronic ISBN: 978-3-319-24112-8. 